\title{
Infrapubic versus Penoscrotal Approaches for Implantation of Semi-Rigid Penile Prosthesis
}

\author{
Salah E. Shebl ${ }^{1}$, Saadeddin Ali ${ }^{2}$ \\ ${ }^{1}$ Urology Department, Faculty of Medicine for Girls, Al-Azhar University, Cairo, Egypt \\ ${ }^{2}$ Andrology and Dermatology Department, Faculty of Medicine, Al-Azhar University, Cairo, Egypt \\ Email: salahshebl@yahoo.com, saadeddin2004@yahoo.com
}

How to cite this paper: Shebl, S.E. and Ali, S. (2017) Infrapubic versus Penoscrotal Approaches for Implantation of Semi-Rigid Penile Prosthesis. Open Journal of Urology, 7, 146-158.

https://doi.org/10.4236/oju.2017.79018

Received: August 9, 2017

Accepted: September 9, 2017

Published: September 12, 2017

Copyright $\odot 2017$ by authors and Scientific Research Publishing Inc. This work is licensed under the Creative Commons Attribution International License (CC BY 4.0).

http://creativecommons.org/licenses/by/4.0/

(c) $\underset{\mathrm{EY}}{\text { (7) Open Access }}$

\begin{abstract}
Background: Modification of surgical techniques to minimize wound infections in penile implant surgery using malleable prosthesis which is easy to use, of very low risk of mechanical failure and is financially suitable to improve outcome and ensures less complications. The aim of the study is to compare infrapubic approach and Penoscrotal approach in penile semi-rigid prosthesis implantation surgery. Patients and methods: Fifty patients were randomly divided into two groups and each group underwent one approach. Results: No statically significant differences were found between both groups in terms of operative time. Corporeal cross over was the most common intraoperative complications, 3 cases in IP approach and 6 cases in PS but not statistically significant. Peyronie's disease patients underwent penile implant through infrapubic approach in 3 cases and PS in 4 cases with one recorded complication of keloid formations with IP. Urethral false passage reported only in one case with PS approach without affecting the procedure. Only minor complications including superficial wound infection which was significantly more with PS, 6/25 (24\%) and IP 1/25 (4\%), p value $=0.041$. Penile and scrotal edema was common with IP approach (92\%) in comparison with PS approach (60\%). The urethral catheter can be abandoned with IP to avoid the risk of catheterizations. No significant relation between diabetes and infections and no erosions were encountered. Conclusion: Through this research work, infrapubic approach is better than Penoscrotal approach even if it is not commonly used by surgeon.
\end{abstract}

\section{Keywords}

Infrapubic, Semi-Rigid, Erectile Dysfunction, Penile Prosthesis, Malleable Implant 


\section{Introduction}

Penile prosthesis is a striking key for patients who do not respond to more conventional therapies. This procedure was considered in patients who not responding to less-invasive treatments or who prefer a lifelong solution to their problem due to its safety, high efficacy, and satisfaction rates [1].

Currently, two existing classes of penile prosthesis include inflatable and semi rigid devices [2].

IP has the advantage of reservoir location under direct vision, but the implantation of the pump may be more challenging, and patients are at a slightly increased risk of penile dorsal nerve injury. The main complications of penile prosthesis implantation are infection, erosion and mechanical failure in inflatable prosthesis [3].

Numerous surgical methods have been designated for implanting penile prostheses: longitudinal penoscrotal, dorsal subcoronal, transverse penoscrotal, the penile proximal, perineal and combined incisions. Infrapubic method was proposed for the device of a three-piece inflatable prosthesis [4].

Semi-rigid penile prosthesis is widely used device. This may be due to low cost, easy application, easy use and less incidence of mechanical complications. The drawbacks of semi-rigid penile implants include permanent erections, inability to mask it and liability for prolonged pain and erosion [5]. There are no available studies to compare infrapubic approach with various approaches for semi-rigid penile implant.

The IP is anticipated to have short operative time, anatomical protection of the urethra and early return to sexual life and less infection in diabetics reducing cutaneous exposure, which diminishes risks of infections, catheterizations and both approaches, may replace each other's in revised cases [6].

This study was designed to compare Infrapubic versus Penoscrotal approaches for the implantation of malleable prostheses as regarding safety, efficacy, duration of recovery, time needed for return to sexual activity, and complications.

\section{Patients and Methods}

\subsection{Study Design and Settings}

This none blinded, double armed, randomized controlled study was conducted at Department of Urology and Andrology, Al-Azhar University, from October 2013 to January 2017.

\subsection{Eligibility}

Fifty men with end stage erectile dysfunction were recruited according to inclusion and exclusion criteria. The inclusion criteria included men with erectile dysfunction not responding to medical treatment and men with vasculogenic impotence in penile duplex. The exclusion criteria were marked obesity (BMI > 35 ), uncontrolled diabetes $(\mathrm{HbAlc}>8)$, patients with previous penile surgery or deformities, patients candidate for re-implant, neurogenic impotence, patients 
with severe obstructive lower urinary tract symptoms (Obstructed uroflow or IPSS > 19), and patients requiring multiple cystoscopies [2] [7].

\subsection{Sample Size Calculation}

The sample was calculated by Epi info 0.7 programs with 2 sided confidence level $95 \%$ at power of $80 \%$. H0 postulated to compare the infrapubic approach against Penoscrotal approach and assuming that type I statistical error is $5 \%$ and type II statistical error in $20 \%$. The estimated sample was 50 patients. The differences between study and control groups were estimated with guarding against drop out.

\subsection{Randomization and Allocation}

Patients were randomly allocated into 2 groups; group I was treated with Infrapubic (IP) approach and group II was treated with Penoscrotal approach (PS). Randomization was done by computer based program. Allocation was done equally by alternate method.

\subsection{Procedures}

Preoperative: All men were given an antibiotic prophylaxis the night before surgery.

\subsection{Surgical Techniques}

All operations were performed by single experienced surgeon and the other surgeon was an assistant. Good sterilization for the operating room the day before the operation. Shaving of genital area pubic and scrotal hair, all procedures were done under spinal anesthesia with penile block and prophylactic antibiotics. In obese patients the incision was close to the penis for easy dissection. Scrubbing by povidone-iodine solution and brushing from umbilicus till knee for 5 - 10 minutes followed by fixation of urethral catheter (in some cases in which we suspect impending obstructive lower urinary tract symptoms) under complete aseptic conditions.

\subsubsection{IP Approach}

Transverse skin incision $2.5-4 \mathrm{~cm}$ was done close to the root of the penis at level of lower border of symphysis pubis (Figure 1). Exposure of the corpora with two retractors avoiding suspensory ligaments and neurovascular bundle is at the middle of the corpora. Artificial erection sometimes was done specially in cases of Peyronie's to determine the degree of curvature. Two lateral stay sutures in starting corpora using silk sutures were applied then vertical $2 \mathrm{~cm}$ corporotomy incision was done. Subtunical Corporeal dilatation with stretching the penis using heggar dilators was directed upwards and laterally specially in non-catheterized patients to avoid injury of the urethra. Measurements were taken distally and proximally on both sides on maximal penile length with avoiding the urethra and distal third of the glans. Frequent irrigation with saline 

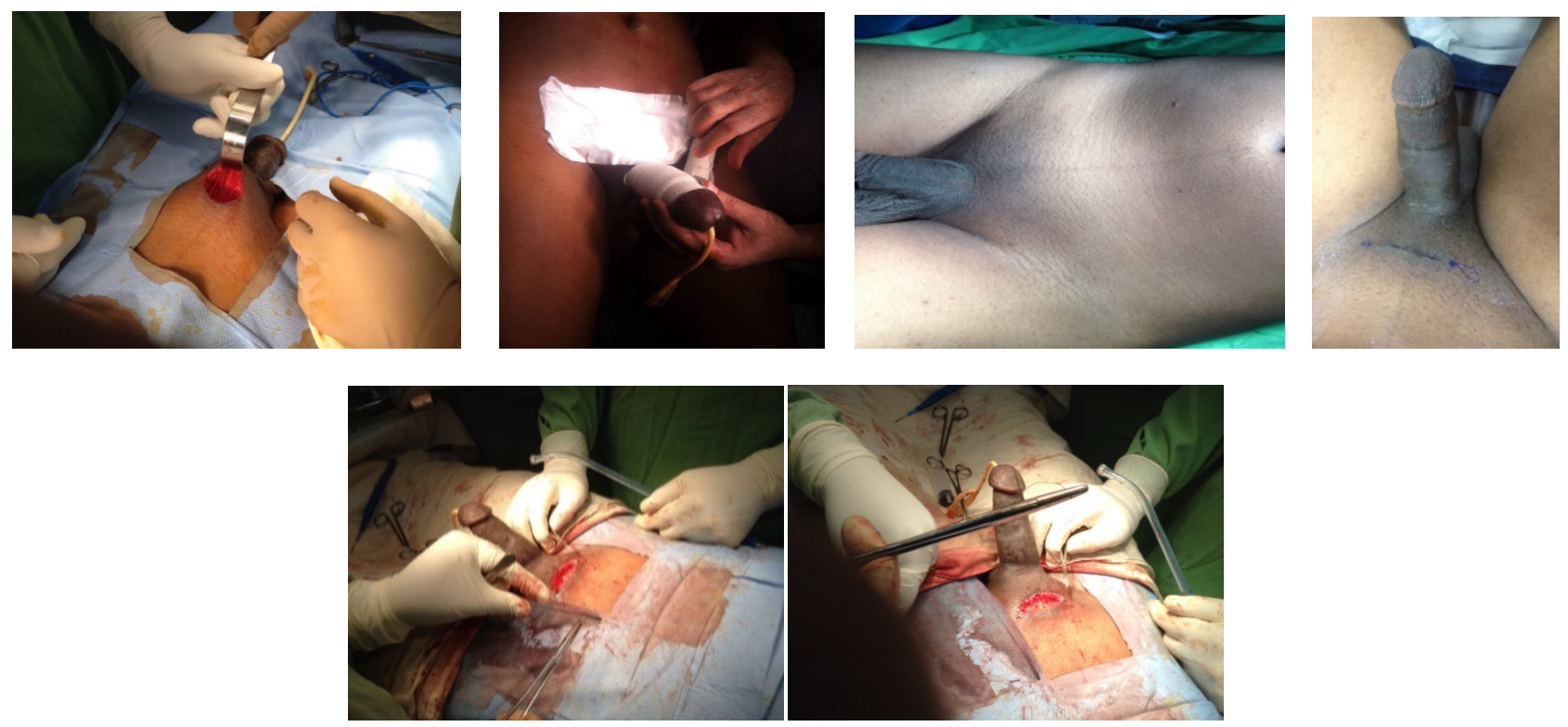

Figure 1. Infrapubic malleable penile prosthesis in diabetic male patient 48 years old.

and Gentamycin proximally and distally was applied. Placement of cylinder after proper measurement both proximally and distally was done. Close corpora on each side in continuous fashion followed by closure of all layers separately. Good homeostasis was done then closure of wound in layers and closure of skin in subcuticular or interrupted half mattress sutures (Figure 1 \& Figure 2) followed by Small Compression paper tape.

\subsubsection{PS Approach}

Incision was designed at penoscrotal junction 2.5 to $4 \mathrm{~cm}$ in length. The corpora of the penis were accessed along the ventral aspect just lateral to the urethra (Figure 4).

\subsection{Post-Operative Care}

Good broad spectrum antibiotic covering gram positive, negative and anaerobic infections were given plus an alpha blocker to relieve expected urinary symptoms. Compression around the penis was applied by wrapping the penis with goose. Urethral catheter was removed then patient was discharged on the same day or the day after the operation according to patient stability. All patients were re-evaluated every week until complete wound healing to assess prosthesis function and complications and further follow up through control visits or by serial whatsApp photos for any changes.

Infection was defined as: purulent discharge from the incision, Wound disruption and fever occurrence.

Edema was defined as: swelling of penis and/or scrotum beyond the accepted range.

Neurovascular bundle preservation is defined by: Avoidance of trauma to the neurovascular bundle of penis. 

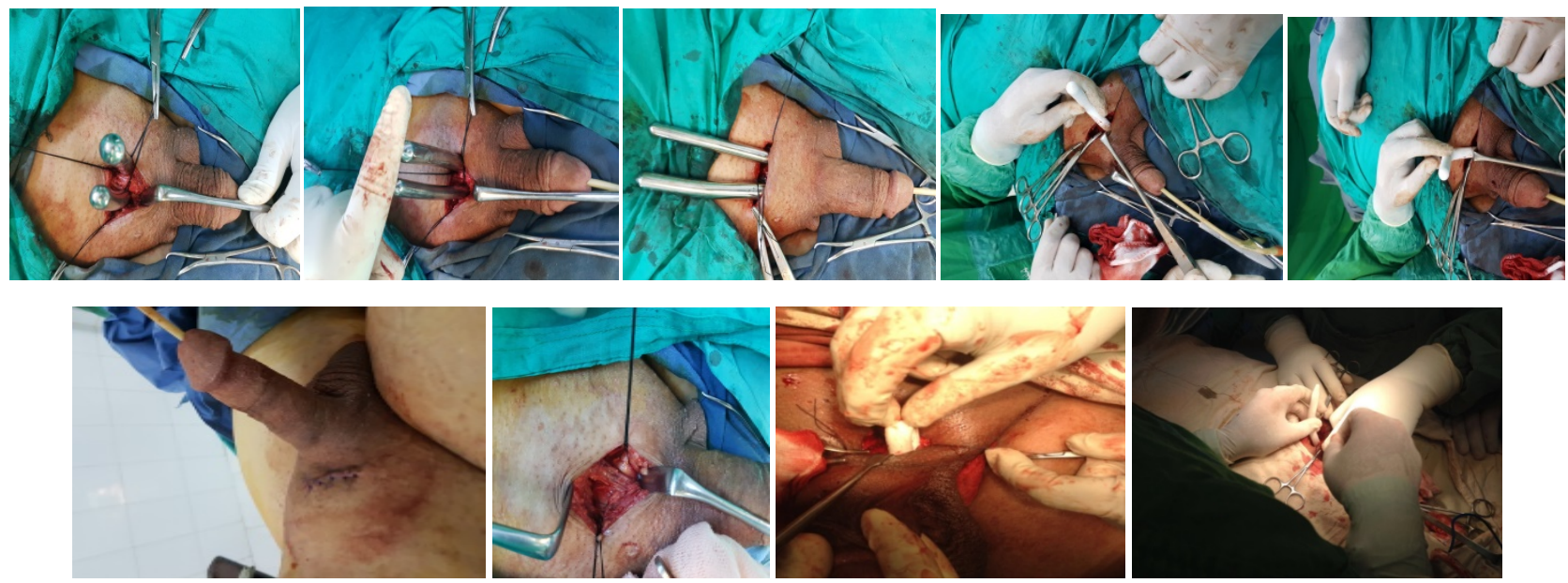

Figure 2. Infrapubic malleable prosthesis in male patient 44 years old. Good preservation ofneurovascular bundle.
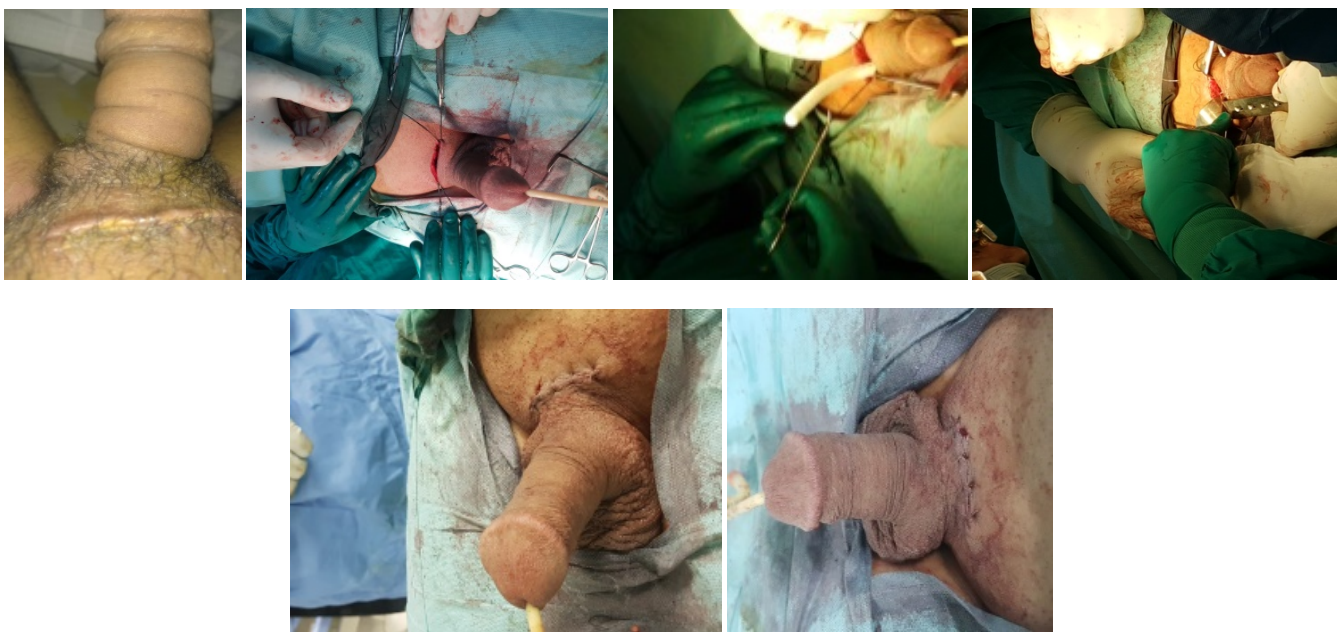

Figure 3. Marked penile edema and keloid formation in patient underwent infrapubic malleable prosthesis in Peyronie's disease.
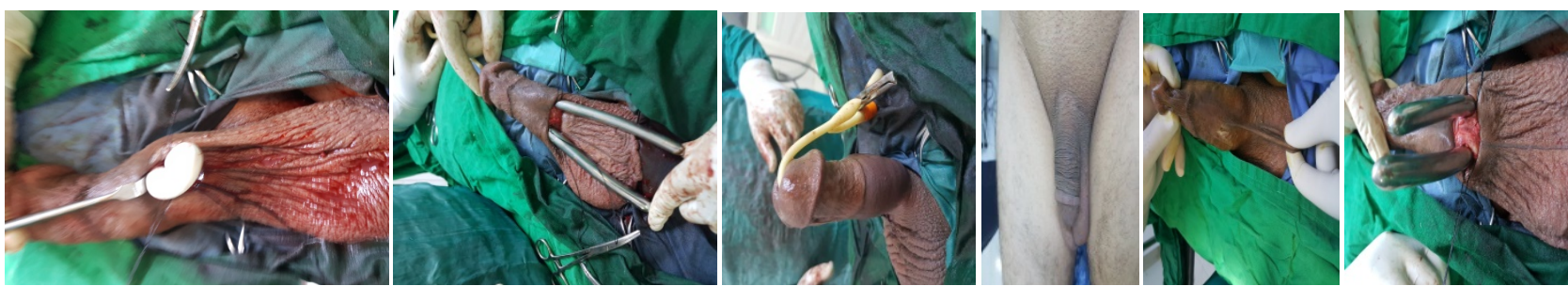

Figure 4. Penoscrotal malleable implant in diabetic male 51 years old.

Cross over was defined as: The implant is on the left side at one end and the cross over to the right side on the other end and vice versa.

Satisfaction was defined as having satisfactory intercourse and happiness with the device in general with no dependence on any questionnaires.

\subsection{Ethical Issues}

This study was approved by the local institutional committee. All patients were counseled and informed consent was obtained from each patient and goals and 
risks of this study were thoroughly explained.

\subsection{Statistical Analysis}

The demographic characters, operative details, intraoperative and postoperative complications were recorded. The success rate and patient satisfaction were also determined. All gathered data were statistically analyzed by Stastical Package of Social Science (SPSS) software version 20. Mean and Standard deviation was calculated for proposed variables. Categorical variables were analyzed using chi-square test. Difference was considered significant if $\mathrm{P} \leq 0.05$.

\section{Results}

This prospective comparative study was conducted on 50 patients who underwent semi-rigid penile prosthesis and were equally randomized into 2 groups, group I underwent IP approach and group II underwent PS approach.

The mean age of patients was 51.2 years (28 to 68 years) who have infrapubic approach and 52.12 years (range: 26 - 66 years) at Penoscrotal (Table 1).

Duplex ultrasound used as diagnostic tool in all patients. The etiology of erectile dysfunction in PS and IP were mainly vasculogenic by calculation of peak systolic and end diastolic velocity in both groups with an erection grade E0 - E2 (Table 2).

Table 1. Demographics and characteristics of both groups.

\begin{tabular}{|c|c|c|c|c|c|c|c|c|c|c|}
\hline & \multicolumn{4}{|c|}{ Infrapubic (No. $=25)$} & \multicolumn{4}{|c|}{ Penoscrotal (No. $=25)$} & \multicolumn{2}{|c|}{ Independent t-test } \\
\hline & Mean & $\mathrm{SD}$ & Min & $\operatorname{Max}$ & Mean & SD & Min & $\operatorname{Max}$ & $\mathbf{t}$ & P-value \\
\hline Age & 51.20 & 9.84 & 28 & 68 & 52.12 & 11.50 & 26 & 66 & -0.304 & 0.763 \\
\hline \multirow[t]{3}{*}{ BMI } & 27.80 & 3.07 & 24 & 33 & 27.20 & 2.45 & 24 & 30 & 0.764 & 0.449 \\
\hline & \multirow{2}{*}{\multicolumn{2}{|c|}{ No. }} & \multirow{2}{*}{\multicolumn{2}{|c|}{$\%$}} & \multirow{2}{*}{\multicolumn{2}{|c|}{ No. }} & \multirow{2}{*}{\multicolumn{2}{|c|}{$\%$}} & \multicolumn{2}{|c|}{ Chi square test } \\
\hline & & & & & & & & & $\mathrm{X}^{2}$ & P-value \\
\hline Hypertension & 12 & & $48.0 \%$ & & 12 & & $48.0 \%$ & & 0.000 & 1.000 \\
\hline Diabetes & 20 & & $80.0 \%$ & & 20 & & $80.0 \%$ & & 0.000 & 1.000 \\
\hline \multicolumn{11}{|c|}{ History of pharmacotherapy For ED } \\
\hline - No & 5 & & $20.0 \%$ & & 4 & & $16.0 \%$ & & 0.136 & 0.713 \\
\hline - Yes & 20 & & $80.0 \%$ & & 21 & & $84.0 \%$ & & & \\
\hline
\end{tabular}

P > 0.05: Non significant (NS), P < 0.05: Significant (S), P < 0.01: Highly Significant (HS); ED: Erectile Dysfunction.

Table 2. Comparison between group I \& group II as regards penile duplex.

\begin{tabular}{|c|c|c|c|c|c|c|c|}
\hline & & \multicolumn{2}{|c|}{ Infrapubic (No. = 25) } & \multicolumn{2}{|c|}{ Penoscrotal $($ No. $=25)$} & \multicolumn{2}{|c|}{ Chi square test } \\
\hline & & No. & $\%$ & No. & $\%$ & $\mathrm{X}^{2}$ & P-value \\
\hline \multirow[t]{2}{*}{ Penile duplex } & Mixed & 5 & $20.0 \%$ & 6 & $24.0 \%$ & 0.359 & 0.836 \\
\hline & Venogenic & 17 & $68.0 \%$ & 15 & $60.0 \%$ & & \\
\hline
\end{tabular}


Peyronie's disease patients underwent penile implant through infrapubic approach in 3 cases and Penoscrotal in 4 cases (Table 3 ).

Most of patients had administrated medical treatments (phosphodiestrase inhibitors type 5) 20 patients in infrapubic and 21 at PS (Table 1). Three patients in each group received local intracorporeal injection. None of patients had tried vacuum device previously in both groups.

No statically significant differences were found between both groups in terms of operative time but size of the incision can be less with PS procedure in term of operative time and day of discharge (Table $4 \&$ Table 5).

The most common intraoperative complications were corporeal cross over 3 cases in IP approach and 6 cases in PS but not statistically significant.

Urethral injury was reported only in one case with Penoscrotal approach in which urethral catheter not used at the start of the operation and during catheterization false passage occurred but the procedure was continued (Table 3 ).

Most of postoperative complications were minor complications including superficial wound infection. Scrotal and penile shaft edema was common with infrapubic approach (92\%) in comparison with Penoscrotal approach (60\%) (Figure 3 \& Table 6). No erosions were encountered.

Table 3. Comparison between group I \& group II as regards Peyronie's disease, corporeal cross over and catheterizations.

\begin{tabular}{|c|c|c|c|c|c|c|c|}
\hline & & \multicolumn{2}{|c|}{ Infrapubic $($ No. $=25)$} & \multicolumn{2}{|c|}{ Penoscrotal $($ No. $=25)$} & \multicolumn{2}{|c|}{ Chi square test } \\
\hline & & No. & $\%$ & No. & $\%$ & $\mathrm{X}^{2}$ & $P$-value \\
\hline \multirow[b]{2}{*}{ Peyronie's disease } & No & 22 & $88.0 \%$ & 21 & $84.0 \%$ & \multirow[b]{2}{*}{0.166} & \multirow[b]{2}{*}{0.684} \\
\hline & Yes & 3 & $12.0 \%$ & 4 & $16.0 \%$ & & \\
\hline \multirow[b]{2}{*}{ Corporeal cross over } & No & 22 & $88.0 \%$ & 19 & $76.0 \%$ & \multirow[b]{2}{*}{1.220} & \multirow[b]{2}{*}{0.269} \\
\hline & Yes & 3 & $12.0 \%$ & 6 & $24.0 \%$ & & \\
\hline \multirow{2}{*}{ Catheterizations } & No & 22 & $88 \%$ & 0 & $0 \%$ & \multirow{2}{*}{39.286} & \multirow{2}{*}{$<0.001$} \\
\hline & Yes & 3 & $12 \%$ & 25 & $100 \%$ & & \\
\hline \multicolumn{2}{|c|}{ Artificial erection } & 3 & $12.0 \%$ & 5 & $20.0 \%$ & 0.595 & 0.440 \\
\hline \multicolumn{2}{|c|}{ Urethral injury } & 0 & $0.0 \%$ & 1 & $4.0 \%$ & 1.020 & 0.312 \\
\hline
\end{tabular}

Table 4. Comparison between group I \& group II as regards day of discharge.

\begin{tabular}{cccccccc}
\hline & & \multicolumn{2}{c}{ Infrapubic (No. = 25) } & \multicolumn{2}{c}{ Penoscrotal (No. = 25) } & \multicolumn{2}{c}{ Chi square test } \\
\cline { 3 - 7 } & & No. & $\%$ & No. & $\%$ & X $^{2}$ & P-value \\
\hline \multirow{2}{*}{ Day of discharge } & 2nd day & 4 & $16.0 \%$ & 5 & $20.0 \%$ & 0.136 & 0.713 \\
& Same day & 21 & $84.0 \%$ & 20 & $80.0 \%$ & & \\
\hline
\end{tabular}

Table 5. Comparison between group I \& group II as regards operative time and size of the incision.

\begin{tabular}{cccccccccccc}
\hline & \multicolumn{3}{c}{ Infrapubic (No. = 25) } & \multicolumn{4}{c}{ Penoscrotal (No. = 25) } & \multicolumn{3}{c}{ Independent t-test } \\
\cline { 2 - 12 } & Mean & SD & Min & Max & Mean & SD & Min & Max & t & P-value \\
\hline Operative time (min) & 96.60 & 24.53 & 60 & 180 & 99.20 & 28.42 & 30 & 180 & -0.346 & 0.731 \\
Size of the incision (cm) & 3.62 & 0.48 & 2.5 & 4 & 3.02 & 0.27 & 2.5 & 4 & 5.410 & $<0.001$ \\
\hline
\end{tabular}


Table 6. Comparison between group I \& group II as regards pain and infection.

\begin{tabular}{|c|c|c|c|c|c|c|c|}
\hline & & \multicolumn{2}{|c|}{ Infrapubic $($ No. $=25)$} & \multicolumn{2}{|c|}{ Penoscrotal $($ No. $=25)$} & \multicolumn{2}{|c|}{ Chi square test } \\
\hline & & No. & $\%$ & No. & $\%$ & $\mathrm{X}^{2}$ & P-value \\
\hline \multirow{2}{*}{ Wound dehiscence } & No & 25 & $100.0 \%$ & 24 & $96.0 \%$ & \multirow{2}{*}{1.020} & \multirow{2}{*}{0.312} \\
\hline & Yes & 0 & $0.0 \%$ & 1 & $4.0 \%$ & & \\
\hline Erosion & No & 25 & $100.0 \%$ & 25 & $100.0 \%$ & NA & NA \\
\hline \multirow{2}{*}{ Edema } & No & 2 & $8.0 \%$ & 10 & $40.0 \%$ & \multirow{2}{*}{7.018} & \multirow{2}{*}{0.008} \\
\hline & Yes & 23 & $92.0 \%$ & 15 & $60.0 \%$ & & \\
\hline \multicolumn{2}{|l|}{ Pain } & 22 & $88.0 \%$ & 19 & $76.0 \%$ & 1.220 & 0.269 \\
\hline \multicolumn{2}{|c|}{ Wound Infection } & 1 & $4.0 \%$ & 6 & $24 \%$ & 4.153 & 0.041 \\
\hline
\end{tabular}

\section{Intraoperative Complication}

Cross over was an encountered complication during corporeal dilatation. It can be easily discovered ( 3 cases in IP and 6 cases in PS) and can be easily managed.

Wound and penile implant infections were reported with PS approach (6 cases) more than IP (only one case) (Table 6).

Mechanical failure of malleable prosthesis such as break was not observed in this study. The follow up period was three months for each patient. Satisfaction with the prosthesis was not evaluated in details in this study, where patients were asked during their visits if they were very satisfied, satisfied or unsatisfied with the prosthesis in general.

\section{Discussion}

The two proposed methods as technical decisions for malleable penile prosthesis despite of presence of inflatable implants were evaluated. In Egypt the semi-rigid implant is commonly used in management of erectile dysfunction not only for its technical facility to be applied and less incidence of mechanical failure but also due to low cost [5]. To our knowledge, most surgeons prefer the Penoscrotal approach during application of malleable implant but infrapubic approach were preferred for inflatable prosthesis [7].

Infections remain the most common and serious surgical complications with the risk of further penile shortening, urethral injury with erosion and tissue loss [8] [9]. Patients affected by diabetes, immunosuppression or spinal cord injury are at increased risk of infectious complications [10].

Caution must be taken during implantation of inflatable and malleable devices through the infrapubic access, to avoid the possibility of injury to neurovascular bundle. On the other hand, the approach through the dorsal surface of the corpora cavernosa has a natural capability of anatomical protection of the urethra and not requiring urethral catheterization. This advantage has a vital role when considering possible causes of pre and postoperative morbidity [11].

The main purpose of the present study was to evaluate the outcome of semirgid penile implant using infrapubic approach (to decrease incidence of infection 
and using semirgid to overcome mechanical failure and high cost of inflatable implant in comparison to Penoscrotal as regard intraoperative and postoperative complications. There were no major complication rates during the operations. Urethral injury was encountered in one case in PS which was occurred during fixation of the catheter and overcome by introducer.

Other complications, e.g., cavernosal crossover and crural perforation, did not lead to stopping of the procedure and were not associated with any morbidity after surgery.

All minor postoperative complications were treated conservatively. In particular, Penoscrotal edema relieved by medical treatment. Edema was marked with infrapubic approach and was around penile shaft and scrotum. Edema was increasing by day and standing and decreasing by relaxation. It may be due to compression of lymphatic vessels and surgical manipulations.

The incidence of superficial wound infection occurred in one case in infrapubic approach and six cases with Penoscrotal. These cases were treated conservatively with broad-spectrum antibiotics and frequent dressing and caused no long-term problems. Erosion of the corpora was not reported. Device infection was knowingly more common in men implanted with an inflatable prosthesis (self-contained, 20\%; three-piece, 15\%) than in men implanted with a semi-rigid prosthesis (5\%). The increased hazard of infection with inflatable prostheses might indicate the longer operative time, increasing the "at risk" period when colonization of the implant could happen [12].

Diabetes was not a major predisposing factor for prosthesis infection (1/20 at IP approach and 4/20 in PS) infection also occur in 2 cases with no diabetes in Penoscrotal method as well, although $80 \%$ (40 cases) of the present patients were diabetic, the proportion of infected patients (5/40) which was non-significant (Tables 7-9). A similar lack of correlation between diabetes and penile prosthesis infection was reported by Montague et al., who reported a $2 \%$ incidence of prosthesis infection in non-diabetic patients and a $2.2 \%$ incidence in diabetics which was parallel to this study [9].

The glycosylated hemoglobin may have a role in identifying diabetic patients at risk of implant infection. Bishop et al found that diabetics with a glycosylated hemoglobin level of $>11.5 \%$ had a greater risk of penile prosthesis infection. On the other hand Wilson et al. found no relationship between glycosylated hemoglobin levels in diabetics and prosthesis infection. In this study uncontrolled diabetes were excluded from the start but infection was common with Penoscrotal

Table 7. Comparison between infections regards diabetes in infrapubic.

\begin{tabular}{ccccccc}
\hline \multirow{2}{*}{ Infrapubic } & \multicolumn{2}{c}{ Non infection } & \multicolumn{2}{c}{ Infections } & \multicolumn{2}{c}{ Chi square test } \\
\cline { 2 - 7 } & No. & $\%$ & No. & $\%$ & $\mathrm{X}^{2}$ & P-value \\
\hline Non diabetic & 5 & $20.8 \%$ & 0 & $0.0 \%$ & 0.260 & 0.610 \\
Diabetic & 19 & $79.2 \%$ & 1 & $100.0 \%$ & & \\
\hline
\end{tabular}


Table 8. Comparison between infections regards diabetes in PS.

\begin{tabular}{ccccccc}
\hline \multirow{2}{*}{ Penoscrotal } & \multicolumn{2}{c}{ Non infection } & \multicolumn{2}{c}{ Infections } & \multicolumn{2}{c}{ Chi square test } \\
\cline { 2 - 7 } & No. & $\%$ & No. & $\%$ & $\mathrm{X}^{2}$ & P-value \\
\hline Non diabetic & 3 & $15.8 \%$ & 2 & $33.3 \%$ & 0.877 & 0.349 \\
Diabetic & 16 & $84.2 \%$ & 4 & $66.7 \%$ & & \\
\hline
\end{tabular}

Table 9. Comparison between infections and diabetes in both groups.

\begin{tabular}{ccccccc}
\hline \multirow{2}{*}{ Both groups } & \multicolumn{2}{c}{ Non infection } & \multicolumn{2}{c}{ Infections } & \multicolumn{2}{c}{ Chi square test } \\
\cline { 2 - 7 } & No. & $\%$ & No. & $\%$ & $\mathrm{X}^{2}$ & P-value \\
\hline Non diabetic & 8 & $18.60 \%$ & 2 & $28.60 \%$ & 0.374 & 0.541 (NS) \\
Diabetic & 35 & $81.40 \%$ & 5 & $71.40 \%$ & & \\
\hline
\end{tabular}

approach which clinically significant but statistically insignificant this may be due to more cutaneous exposure and suture overlapping [13] [14].

The present study was not designed to estimate partner satisfaction, but to evaluate the function, incidence of infection and using new substitutes for the usual incision to decrease the infection. Removal of the prosthesis as a result of infection, erosion, or mechanical failure is the main cause for patient dissatisfaction which was not encountered in our study but dissatisfaction with a malleable prosthesis was often for minor reasons.

However, the gold standard 'for treatment of permanent organic ED is implantation of a penile prosthesis. Three-piece inflatable prostheses are easier to conceal and can deliver a Para physiological erection, but malleable prostheses are a possible therapeutic substitute. Three-piece inflatable prostheses are more expensive and have a higher risk of device infection and mechanical failure. Malleable prostheses are more economic and have a lower rate of removal (with a low infection rate and less mechanical failure) but higher rates of patient dissatisfaction with the prosthesis in situ [15].

Problems of penile prosthesis implantation continued to decrease as mechanical malfunctions have been declined as a result of re-engineering penile prostheses. Penile prostheses continue to be reliable, effective methods for reestablishing erectile function with high satisfaction rates [16].

A study suggested that placing suction drains to reduce hematoma was not associated with an increased infection risk and, therefore, recommended [17]. Another study has demonstrated that performing implant surgery as a day-case procedure is associated with equal outcomes and notably reduces the cost [18]. In this study no suctions drains were used and most patients discharged in the same day or the day after the procedure (Table 10).

In Peyronie's disease, corporal scarring not only leads to a bent in the penis but may also result in impaired erectile function. In this situation, insertion of a penile prosthesis has been used to correct both problems by effectively straightening the penis with the implant inflated and using it as a splint so that the pe- 
Table 10. Comparison between group I \& group II as regards use of analgesics, post-operative drain and glans bowing.

\begin{tabular}{|c|c|c|c|c|c|c|c|}
\hline & & \multicolumn{2}{|c|}{ Infrapubic $($ No. $=25)$} & \multicolumn{2}{|c|}{ Penoscrotal $($ No. $=25)$} & \multicolumn{2}{|c|}{ Chi square test } \\
\hline & & No. & $\%$ & No. & $\%$ & $\mathrm{X}^{2}$ & $P$-value \\
\hline \multirow{2}{*}{ Use of analgesics } & No & 4 & $16.0 \%$ & 5 & $20.0 \%$ & \multirow{2}{*}{0.136} & \multirow{2}{*}{0.713} \\
\hline & Yes & 21 & $84.0 \%$ & 20 & $80.0 \%$ & & \\
\hline Post-operative drain & No & 25 & $100.0 \%$ & 25 & $100.0 \%$ & NA & NA \\
\hline \multirow{2}{*}{ Glans bowing } & No & 24 & $96.0 \%$ & 24 & $96.0 \%$ & \multirow{2}{*}{0.000} & \multirow{2}{*}{1.000} \\
\hline & Yes & 1 & $4.0 \%$ & 1 & $4.0 \%$ & & \\
\hline
\end{tabular}

nis heals straight. Long-term results are encouraging. The use of multiple relaxing incisions in the tunica as an alternative to re-modeling also shows promise. [19] In this study small number of patients presented with Peyronie's didn't allow for better evaluations but there is no complications encountered in patients with Peyronie's (Table 3).

Limitations of the study were the small sample of patients (due to low sample of patients fulfilling the inclusion criteria), long term follow up were needed to assess late complications and more details about patient's satisfactions were requested.

\section{Conclusion}

The infrapubic approach is an effective method and should be considered and widely applied as a technical option for implanting malleable prostheses in cases with erectile dysfunction due to vasculogenic causes.

\section{References}

[1] Antonini, G. (2016) Minimally Invasive Infrapubic Inflatable Penile Prosthesis Implant for Erectile Dysfunction: Evaluation of Efficacy, Satisfaction Profile and Complications. International Journal of Impotence Research, 28, 4. https://doi.org/10.1038/ijir.2015.33

[2] Montague, D.K. (2011) Penile Prosthesis Implantation in the Era of Medical Treatment for Erectile Dysfunction. Urologic Clinics of North America, 38, 217. https://doi.org/10.1016/j.ucl.2011.02.009

[3] Hatzimouratidis, G.F, Moncada, I., Muneer, A., Salonia, A. and Verze, P. (2017) Eau Guidelines on Male Sexual Dysfunction: Erectile Dysfunction and Premature Ejaculation. European Association of Urology, Arnhem.

[4] Trost, L.W., Boonjindasup, A.G. and Hellstrom, W.J.G. (2014) Comparison of Infrapubic versus Transcrotal Approaches for Inflatable Penile Prosthesis Placement: A Multi-Institution Report. International Journal of Impotence Research, 27, 86-89. https://doi.org/10.1038/ijir.2014.35

[5] Fathy, A., Shamloul, R., AbdelRahim, A., Zeidan, A., El-Dakhly, R. and Ghanem, H. (2007) Experience with Tube (Promedon) Malleable Penile Implant. Urologia Internationalis, 79, 244-247. https://doi.org/10.1159/000107957

[6] Karpman, E. (2012) Streamlined Approach for Infrapubic Placement of an Inflatable Penile Prosthesis. Advances in Urology, 2012, Article ID 520180, 4. 
https://doi.org/10.1155/2012/520180

[7] Perito, P.E. (2008) Minimally Invasive Infrapubic Inflatable Penile Implant. The Journal of Sexual Medicine, 5, 27-30. https://doi.org/10.1111/j.1743-6109.2007.00682.x

[8] Carson, C.C. (2003) Diagnosis, Treatment and Prevention of Penile Prosthesis Infection. International Journal of Impotence Research, 15, S139-S146. https://doi.org/10.1038/sj.ijir.3901091

[9] Montague, D.K., Angermeier, K.W. and Lakin, M.M. (2001) Penile Prosthesis Infections. International Journal of Impotence Research, 13, 326-328.

https://doi.org/10.1038/sj.ijir.3900768

[10] Carson, C.C. (1988) Infections in Genitourinary Prostheses. Urologic Clinics of North America, 16, 139-147.

[11] Berg, O.D. (2011) Infrapubic Approach for Malleable Penile Implant. International Brazilian Journal of Urology, 37, 94-99. https://doi.org/10.1590/S1677-55382011000100012

[12] Cumming, J. and Pryor, J.P. (1991) Treatment of Organic Impotence. British Journal of Urology, 67, 640-643. https://doi.org/10.1111/j.1464-410X.1991.tb15231.X

[13] Bishop, J.R., Moul, J.W., Sihelnik, S.A., Peppas, D.S., Gormley, T.S. and McLeod, D.G. (1992) Use of Glycosylated Hemoglobin to Identify Diabetics at High Risk for Penile Periprosthetic Infections. Journal of Urology, 147, 386-388.

[14] Wilson, S.K., Carson, C.C., Cleves, M.A. and Delk, J.R. (1998) Quantifying Risk of Penile Prostheses Infection with Elevated Glycosylated Hemoglobin. Journal of Urology, 159, 1537-1540. https://doi.org/10.1097/00005392-199805000-00034

[15] Minervinia, A., Ralph, D.J., John, P. and Pryor, J.P. (2005) Outcome of Penile Prosthesis Implantation for Treating Erectile Dysfunction: Experience with 504 Procedures. BJU International, 97, 129-133. https://doi.org/10.1111/j.1464-410X.2005.05907.x

[16] Anafarta, K., Safak, M., Bedük, Y., Baltaci, S. and Aydos, K. (1996) Clinical Experience with Inflatable and Malleable Penile Implants in 104 Patients. Urologia Internationalis, 56, 100-104. https://doi.org/10.1159/000282820

[17] Sadeghi-Nejad, H., Ilbeigi, P., Wilson, S.K., Delk, J.R., Siegel, A., Seftel, A.D., et al. (2005) Multi-Institutional Outcome Study on the Efficacy of Closed-Suction Drainage of the Scrotum in Three-Piece Inflatable Penile Prosthesis Surgery. International Journal of Impotence Research, 17, 535-538. https://doi.org/10.1038/sj.ijir.3901354

[18] Mulhall, J.P. and Bloom, K. (2001) Comparison of In-Patient and Out-Patient Penile Prosthesis Surgery. International Journal of Impotence Research, 13, 251. https://doi.org/10.1038/sj.ijir.3900695

[19] Sadeghi-Nejad, H. and Fam, M. (2013) Penile Prosthesis Surgery in the Management of Erectile Dysfunction. Arab Journal of Urology, 11, 245-253. 


\section{List of Abbreviations}

IP: infrapubic

PS: Penoscrotal

BMI: Body mass index

IPSS: International prostatic symptoms score

SPSS: Stastical Package of Social Science

ED: Erectile Dysfunction

Submit or recommend next manuscript to SCIRP and we will provide best service for you:

Accepting pre-submission inquiries through Email, Facebook, LinkedIn, Twitter, etc. A wide selection of journals (inclusive of 9 subjects, more than 200 journals) Providing 24-hour high-quality service User-friendly online submission system Fair and swift peer-review system Efficient typesetting and proofreading procedure Display of the result of downloads and visits, as well as the number of cited articles Maximum dissemination of your research work

Submit your manuscript at: http://papersubmission.scirp.org/ Or contact oju@scirp.org 